\title{
Transforming properties of chimeric TEL-JAK proteins in Ba/F3 cells
}

Virginie Lacronique, Anthony Boureux, Richard Monni, Stephanie Dumon, Martine Mauchauffé, Patrick Mayeux, Fabrice Gouilleux, Roland Berger, Sylvie Gisselbrecht, Jacques Ghysdael, and Olivier A. Bernard

The involvement of the cytokine signaling pathway in oncogenesis has long been postulated. Recently, rearrangements of the gene encoding the tyrosine Janus kinase 2 (JAK2) have been reported in human leukemias indicating a direct JAKsignal transduction and activator of transcription (STAT)-mediated leukemic process. The leukemia-associated TEL-JAK2 fusion protein is formed by the oligomerization domain of the translocated ets leukemia (TEL) protein fused to the catalytic domain of JAK2. TEL-mediated oligomerization results in a constitutive tyrosine kinase activity that, in turn, is able to confer growth factor independence to the murine hematopoietic interleukin-3 (IL-3)dependent $\mathrm{Ba} / \mathrm{F} 3$ cell line. Results of the present study indicate that fusion proteins containing the oligomerization domain of TEL and the tyrosine kinase domains of Jak1, Jak2, JAK3, or TYK2 share similar properties and are able to efficiently substitute for the survival and mitogenic signals controlled by IL-3, without concomitant activation of the IL-3 receptor. Electrophoretic mobility shift assays demonstrated Stat 5 as the only activated Stat factor in TEL-Jak2- and TEL-Jak1-expressing cells, whereas other Stats, namely Stat1 and Stat3, could be detected in TEL-JAK3-, TEL-TYK2-, and also in TEL-ABL-expressing $\mathrm{Ba} / \mathrm{F} 3$ cells. High levels of expression of the Stat5target genes pim-1, osm, and Cis were observed in all the cytokine-independent cell lines. Furthermore, the expression of a dominant negative form of Stat5A markedly interfered with the growth factor independence process mediated by TEL-Jak2 in $\mathrm{Ba} / \mathrm{F} 3$ cells. Because the BCR-ABL and TEL-PDGF $\beta R$ oncoproteins also activate Stat5, activation of this factor should be a crucial step in activated tyrosine kinase-mediated leukemogenesis. (Blood. 2000;95:2076-2083)

(1) 2000 by The American Society of Hematology

\section{Introduction}

The Janus kinases (JAK) are receptor-associated tyrosine kinases involved in intracellular signaling pathways of a wide variety of cytokine and growth factor receptors (for a review, see Ihle et $\mathrm{al}^{1}$ ). Four members of the JAK kinase family have been identified in mammals: JAK1, JAK2, and TYK2, which are ubiquitously expressed, and JAK3 whose expression is predominant in hematopoietic cells. Structural similarities shared by the JAK proteins define 7 JAK homology regions (JH1-7, Figure 1). Among these, the $\mathrm{JH} 2$ region is a pseudocatalytic domain, lacking enzymatic activity but assumed to serve as a regulatory region for the JAK activity and as an anchoring region for substrates and regulatory proteins. The JH1 region located at the carboxy-terminus is endowed with tyrosine kinase activity. JAKs are transiently activated following ligand binding and they subsequently phosphorylate multiple substrates, including the JAKs themselves, the cytoplasmic domain of cytokine-receptors, adapter proteins, tyrosine phosphatases, and the signal transducers and activators of transcription (STAT). STATs form a family of cytoplasmic transcription factors that comprise 7 proteins in mammals (Stat 1-4, 5A, 5B, and 6). STATs are activated by the JAKs, form homodimers or heterodimers, and translocate to the nucleus where they participate to transcriptional regulation (for reviews, see Darnell ${ }^{2}$ and Pellegrini and Dusanter-Fourt ${ }^{3}$ ).

Deregulation of the JAK-STAT signaling pathway has often been associated with cellular transformation, although its relevance to oncogenic processes was not clearly established. For example, constitutive activation of STATs and JAKs is a recurrent observation in cell lines transformed by viruses and oncogenes and in human leukemic blood samples (reviewed in Garcia and Jove ${ }^{4}$ ). Furthermore, Stat 3 is required in v-src-mediated transformation of fibroblasts. ${ }^{5,6} \mathrm{~A}$ direct link between JAK deregulation and malignant transformation has recently been established by the rearrangement of the JAK2 gene as the result of specific chromosomal translocations in human leukemias. These translocations result in the fusion of various parts of JAK 2 to the amino-terminal region of the Translocated Ets Leukemia (TEL) protein, whose gene is frequently rearranged in human malignancies. 7,8 The resulting fusion proteins always include the JAK2 catalytic domain. The NH2-terminal Conserved Region (NCR) of TEL has been shown to mediate homotypic oligomerization of the TEL-Jak2 protein leading to constitutive tyrosine kinase activity. The fusion protein exhibits transforming properties, as judged by its ability to relieve the growth factor dependency of murine hematopoietic $\mathrm{Ba} / \mathrm{F} 3$ cells. ${ }^{7}$ Similar properties have been shown to be critical for the transforming properties of several neoplasia-associated tyrosine kinases fused to TEL, such as TEL-ABL ${ }^{9}$ and TEL-PDGF $\beta$ R. $^{10,11}$ These activated kinases are similarly supposed to mimic growth
From U434 INSERM, Centre d'Etude du Polymorphisme Humain (CEPH), Paris, France; UMR 146 CNRS, Institut Curie-Section Recherche, Centre Universitaire, Orsay, France; U363 INSERM, Institut Cochin de Génétique Moléculaire (ICGM), Université René Descartes, Paris, France.

Supported in part by grants from the Association contre le Cancer (ARC), the Ligue Nationale contre le Cancer (LNCC), and the Comite de Paris of the LNCC. R.M. and S.D. are supported by a Ministère de l'Education Nationale, de la Recherche et des Technologies (MENRT) fellowship.
Submitted May 27, 1999; accepted October 28, 1999.

Reprints: O. A. Bernard, U434 INSERM-CEPH, 27 rue Juliette Dodu, 75010 Paris, France; e-mail: olivier.bernard@cephb.fr.

The publication costs of this article were defrayed in part by page charge payment. Therefore, and solely to indicate this fact, this article is hereby marked "advertisement" in accordance with 18 U.S.C. section 1734.

(c) 2000 by The American Society of Hematology 
A

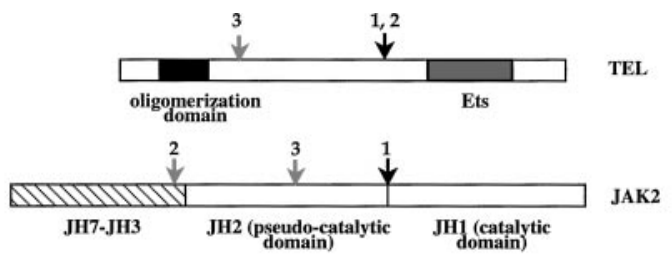

B

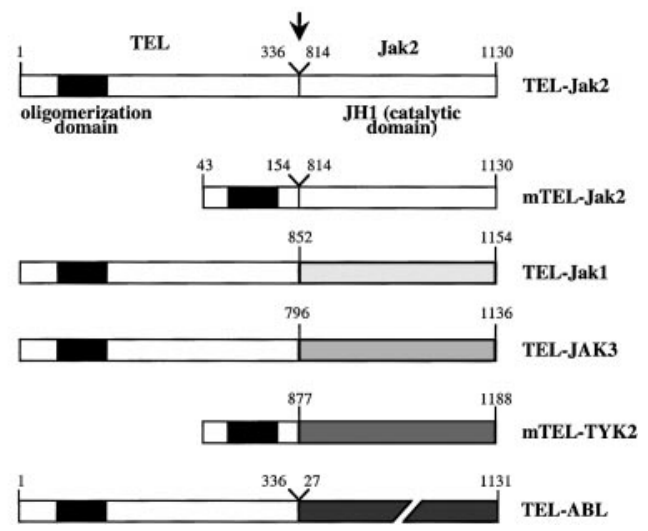

Figure 1. Schematic structure of TEL-JAK fusion proteins. (A) Schematic of TEL and JAK2 proteins. The TEL oligomerization domain is represented by a hatched box. Arrows indicate the location of the fusion points characterized in human leukemias, as reported in work by Lacronique et $\mathrm{al}^{7}$ and Peeters et al. ${ }^{8} 1,: \mathrm{T} \mathrm{ALL} ; 2$, atypical CML; 3, pre-B ALL; JH, JAK homology region. (B) TEL-JAK fusion proteins constructed by linking the 336 amino-terminal amino acids of human TEL to the tyrosine kinase domain of murine Jak2 (TEL-Jak2), murine Jak1 (TEL-Jak1), and human JAK3 (TEL-JAK3). Amino acids 53 to 154 of TEL are fused to the corresponding JH1 domains in mTEL-Jak2 and mTEL-TYK2 (human TYK2) constructs. The fusion points in the different chimera are indicated by an arrow. The human TEL-ABL fusion has been previously reported. ${ }^{9}$ Amino acids numbering on the $\mathrm{JH} 1$ part of TEL-JAK fusions refers to the sequences of the wild type JAKs.

factor action on cellular processes, mainly proliferation and inhibition of apoptosis.

We studied TEL-JAK chimeric proteins consisting of the catalytic domains of Jak1, Jak2, JAK3, and TYK2 fused to the NCR domain of TEL. Oligomerization of the JAK kinase domains through the NCR domain resulted in constitutive tyrosine kinase activity of TEL-JAK chimeras and in the activation of their transforming properties, similar to those of the TEL-Jak2 fusion. Stat5 activation was observed in cells transformed by all TEL-JAK kinases and shown to be essential to the mitogenic properties of TEL-Jak2.

\section{Materials and methods}

\section{Plasmids}

The TEL-Jak2 fusion complementary DNA (cDNA) has been described previously. ${ }^{7}$ The mTEL-Jak2 fusion (see Figure 1) was constructed from TEL-Jak2 by polymerase chain reaction (PCR)-mediated amplification of the appropriate regions of human TEL (amino acids 43-154) linked to the $318 \mathrm{COOH}$-terminal amino acids of murine Jak2. The TEL-Jak1 and TEL-JAK3 cDNAs were constructed by PCR-mediated amplification to encode the $336 \mathrm{NH} 2$-residues of TEL and the 302 and $341 \mathrm{COOH}$-terminal residues of murine Jak1 and human JAK3, respectively. The mTEL-TYK2 construct was obtained by splitting together a mTEL-Jak2 clone and a PCR-generated fragment spanning the $311 \mathrm{COOH}$-terminal residues of human TYK2. PCR products were subsequently showed to be devoid of mutations by sequencing. Jak1, JAK3, and TYK2 cDNAs were gifts from H. Beug, J. J. O'Shea, and S. Pellegrini, respectively. The human TEL-ABL
cDNA was kindly provided by D. G. Gilliland. TEL-ABL and TEL-JAK cDNAs were subcloned into the retroviral $\mathrm{pBabeNeo}$ vector for stable transfections in $\mathrm{Ba} / \mathrm{F} 3$ cells.

\section{Cell culture, interleukin-3 independence, and transfections}

$\mathrm{Ba} / \mathrm{F} 3$ cells were grown in RPMI 1640 medium containing $10 \%$ fetal bovine serum and 5\% WEHI conditioned medium as a source of interleukin-3 (IL-3). For IL-3 stimulation, Ba/F3 cells were starved for 5 hours in Iscove modification of Dulbecco's minimum essential medium containing $0.4 \%$ bovine serum albumin and $20 \mu \mathrm{g} / \mathrm{mL}$ iron-saturated transferrin, then stimulated with $10 \mathrm{ng} / \mathrm{mL}$ of recombinant murine IL-3 (R and D Systems, Abingdon, UK) for 10 minutes. Deprived $\mathrm{Ba} / \mathrm{F} 3$ cells were maintained in the same medium for 15 hours. Stably TEL-JAK-transfected Ba/F3 cells were obtained by electroporation (Bio-Rad Gene Pulsar, Ivry-sur-Seine, France) and selected for transformants with $1 \mathrm{mg} / \mathrm{mL}$ neomycin. For IL-3-independent proliferation assays, G418-resistant $\mathrm{Ba} / \mathrm{F} 3$ transfectants were seeded in IL-3-free medium in 96-well plates as previously reported. ${ }^{7}$ Mock-transfected cells and transfectants harboring the pBabeNeo vector alone were used as controls. The $\mathrm{Ba} / \mathrm{F} 3$ cell line constitutively expressing a dominant negative form of Stat5A (Stat5A $\Delta 749$ ) from the pRSVNeo vector has been previously reported. ${ }^{12}$ The TEL-Jak2 cDNA was cloned into the retroviral pBabePuro vector and stably transfected into $\mathrm{Ba} / \mathrm{F} 3$ cells expressing Stat5A $\Delta 749$ from pRSV vector and in control pRSVNeo-Ba/F3 cells. Transfectants were selected in the presence of $1 \mu \mathrm{g} / \mathrm{mL}$ puromycine. For IL-3-independent proliferation assays, Ba/F3 cells expressing either TEL-Jak2 or Stat5A $\Delta 749$, or coexpressing Stat5A $\Delta 749+$ TEL-Jak2 and Stat5A $\Delta 749$ cells transfected with the empty pBabePuro vector (Stat5A $\Delta 749+$ pBabePuro) were washed twice in WEHI-free medium then seeded in the same medium at a density of $10^{5} \mathrm{cells} / \mathrm{mL}$. Proliferation rates of the different cell lines were monitored daily by using a Coulter analyzer (Coultertronics, Margency, France). The growth slope presented is representative of duplicates of 2 independent experiments.

\section{Nuclear extracts and electrophoretic mobility shift assays}

Nuclear extracts were made as reported previously. ${ }^{13}$ For electrophoretic mobility shift assays (EMSA), $20 \mu \mathrm{L}$ of nuclear extracts from TEL-ABL and TEL-JAK-transformed $\mathrm{Ba} / \mathrm{F} 3$ cells were incubated with the ${ }^{32} \mathrm{P}$-labeled m67SIE 5' -CATTTCCCGTAAATC-3' and bovine $\beta$-casein $5^{\prime}$-AGATTTCTAGGAATTCAAATC-3' STAT binding sites. Eight microliters of nuclear extracts from murine IL-3-stimulated parental $\mathrm{Ba} / \mathrm{F} 3$ cells were used as controls. Supershift assays were performed by using anti-Stat1 (Transduction Laboratories, Lexington, KY), anti-Stat3 (Santa Cruz Biotechnology, Inc, Le Perray-en Yvelines, France) and anti-Stat5 antibodies. ${ }^{14}$

Stat 4 and Stat6 DNA binding activities were investigated, using the specific Fc $\gamma$ RI 5'-AGCATGTTTCAAGGATTTGAGATGTATTTCCCAGAAAAG-3') and I $\epsilon$ 5'-GTCAA CTTCCCAAGAACAGAA-3') probes. Extracts of COS7 cells co-transfected with TEL-Jak2 and Stat 4 or Stat6 expression vectors (a kind gift of J. R. Darnell) were used as positive controls.

\section{Northern blots}

Northern blotting analysis was performed by using $10 \mu \mathrm{g}$ of total RNA and probes corresponding to murine cDNA fragments for pim-1, osm, cis, c-myc, c-jun, and c-fos labeled with ${ }^{32} \mathrm{P}-\alpha \mathrm{CTP}$ by random-priming. Northern blots were normalized by hybridization with a GAPDH probe. Radioactivity was quantified using a Molecular Imager (Bio-Rad)

\section{Cell lysates, immunoprecipitates, and Western blot analyses}

For Western blotting of total cell lysates, $\mathrm{Ba} / \mathrm{F} 3$ cells were lysed in $1 \%$ Brij 96, $10 \mathrm{mM}$ Tris/Hcl pH 7.4, $150 \mathrm{mM} \mathrm{NaCl}, 5 \mathrm{mM}$ EDTA, $10 \%$ glycerol, $0.02 \% \mathrm{NaN}_{3}$, and $1 \mathrm{mM} \mathrm{Na} \mathrm{VO}_{4}$. Whole cell lysates were cleared by centrifugation at $13000 \mathrm{~g}$ for 20 minutes at $4^{\circ} \mathrm{C}$ and $50 \mu \mathrm{g}$ of cellular protein was separated through $10 \%$ sodium dodecyl sulfate (SDS)-polyacrylamide gels, transferred to nitrocellulose, and blotted with an antiphosphotyrosine antibody 4G10 (Upstate Biotechnology, Inc, Souffelweyersheim, France). For IL-3 receptor $\beta$ subunit (IL-3 $\beta R$ ) immunoprecipitation analysis, $20 \times$ $10^{6} \mathrm{Ba} / \mathrm{F} 3$ cells were lysed in the above buffer and supernatants were 
incubated 2 hours at $4{ }^{\circ} \mathrm{C}$ with a rabbit polyclonal anti-IL-3ßR antibody (Santa Cruz Biotechnology, Inc.). Immunoprecipitates were separated by 8\% SDS-polyacrylamide gels, transferred to nitrocellulose, and blotted with antiphosphotyrosine and anti-IL-3 $\beta R$ subunit antibodies. Expression of stably transfected TEL-JAK and TEL-ABL fusions in Ba/F3 cells was evaluated by immunoprecipitation followed by Western blot analysis, using a rabbit polyclonal immunoserum raised against the amino-terminal part of the human TEL protein $(\alpha \mathrm{N} \text {-TEL })^{15}$ present in all the chimeras. Immunocomplexes were detected using the ECL detection kit (Amersham, Orsay, France). Stripping and probing were performed according to the manufacturer's instructions.

\section{Results}

TEL-JAK fusion proteins exhibit constitutive tyrosine kinase activity and confer factor-independent growth to IL-3-dependent $\mathrm{Ba} / \mathrm{F} 3$ cells

To investigate for potential biologic differences between the tyrosine kinase domains (JH1) of JAK family members, we generated chimeric proteins modeled on the structure of the oncogenic TEL-Jak2 fusion in which the JH1 domains of JAK1, JAK3, and TYK2 were fused to TEL sequences. The schematic structures of these TEL-JAK proteins are summarized in Figure 1. All TEL-JAK fusions include the NCR region of TEL responsible for the homotypic oligomerization of TEL and TEL-derived fusion proteins. To determine if TEL sequences outside of the NCR contribute to transformation, a truncated mTEL-Jak2 fusion was constructed, directly linking the NCR region to the JH1 of Jak2. The murine TEL-TYK2 chimeric protein was constructed similarly to the above fusion. Western blotting analysis using antiphosphotyrosine antibody showed the constitutive phosphorylation of in vitro produced TEL-JAK chimeras (data not shown), a property known to reflect the intrinsic tyrosine kinase activity of the chimeric proteins. ${ }^{7,10}$ These results confirm that oligomerization of the catalytic domains of JAKs through the NCR domain of TEL is sufficient to allow their constitutive activation.

To test for the transforming capacities of these proteins, TEL-JAK fusions were stably expressed in $\mathrm{Ba} / \mathrm{F} 3$ cells using a pBabeNeo retroviral vector. The truncated mTEL-Jak2 fusion was equivalent to the full-length protein regarding its ability to transform $\mathrm{Ba} / \mathrm{F} 3$ cells, thus indicating that most of the TEL sequences present in the initial chimera do not significantly contribute to its transforming properties in this model. All TEL-JAK chimera were expressed at similar levels (Figure 2A), tyrosine phosphorylated, and found to confer IL-3 independence to $\mathrm{Ba} / \mathrm{F} 3$ cells without significant variation of cell growth rates between the different transformed cell lines (data not shown). TEL-JAK-transformed cell lines grew identically when maintained with or without a source of IL-3, indicating that chimeric proteins efficiently substitute for the mitogenic and antiapoptotic signals controlled by the cytokine. Growth factor independence was readily obtained in TEL-ABLexpressing $\mathrm{Ba} / \mathrm{F} 3$ cells, as previously reported. ${ }^{9}$

\section{The TEL-JAK proteins do not significantly phosphorylate tyrosine residues of the IL-3 $\beta R$ chain}

Phosphorylation of the tyrosine residues in the intracellular domain of cytokine receptors are known to be controlled by JAK kinases. Because the growth factor independence of $\mathrm{Ba} / \mathrm{F} 3$ cells expressing TEL-tyrosine kinase fusions could result from the activation of the IL-3 receptor, we analyzed the phosphorylation state of the IL-3 $\beta R$ by phosphotyrosine immunoblotting after immunoprecipitation of

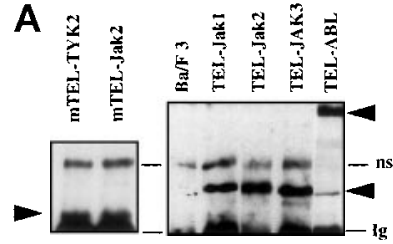

IP : $\alpha$ N-TEL WB: $\alpha$ N-TEL

B
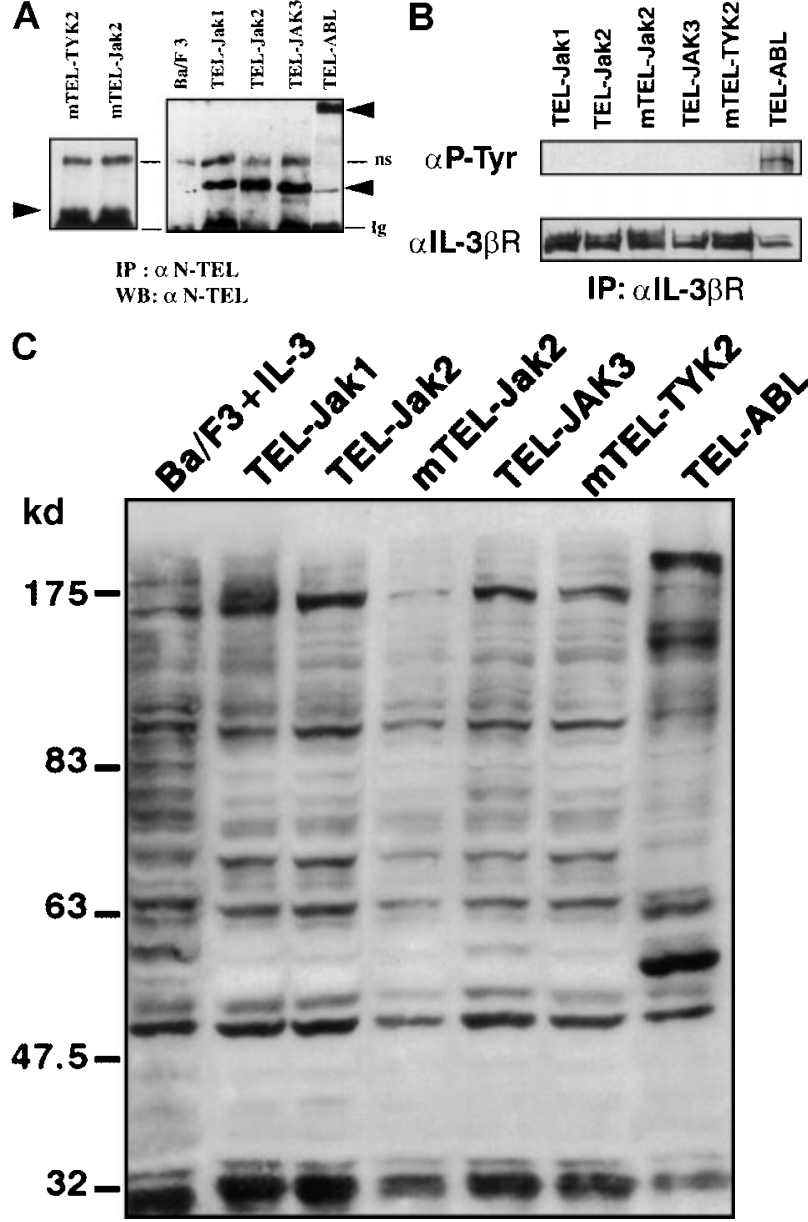

Figure 2. Phosphotyrosine immunoblot analysis of the IL-3 receptor $\beta$ subunit and of cellular proteins in TEL-JAK- and TEL-ABL-expressing cells. (A) The expression of stably transfected TEL-JAK and TEL-ABL fusions in the indicated IL-3-independent $\mathrm{Ba} / \mathrm{F} 3$ cell lines was evaluated by immunoprecipitation (IP) followed by Western blotting (WB) using a polyclonal rabbit immune serum raised against the amino-terminal part ( $\alpha \mathrm{N}$-TEL) of the human TEL protein. Immunoprecipitated complexes are indicated by black arrows; ns, nonspecific. Predicted molecular weights of the chimera are as follows: TEL-Jak1, $75.5 \mathrm{kd}$; TEL-Jak2, $77.7 \mathrm{kd}$; TEL-JAK3, 79.3 kd; TEL-ABL, 158.8 kd; murine TEL-Jak2, 50.5 kd; murine TELTYK2, $49.4 \mathrm{kd}$. (B) The IL-3 $\beta$ R subunit was immunoprecipitated from total cell lysates of the indicated IL-3-independent Ba/F3 cell lines and analyzed by immunoblotting with an antiphosphotyrosine antibody ( $\alpha$ pTyr). The blot was stripped and reprobed with an anti-IL-3 $\beta R$ antibody. (C) Total cell lysates of the indicated IL-3-independent $\mathrm{Ba} / \mathrm{F} 3$ cells were subjected to Western blotting using an antiphosphotyrosine antibody. As a control, total cell lysates of parental $\mathrm{Ba} / \mathrm{F} 3$ cells, starved then stimulated with $\mathrm{mIL}-3$, were loaded. Differences in patterns of cellular protein phosphorylations were reproducibly observed between TEL-JAK- and TEL-ABLexpressing $\mathrm{Ba} / \mathrm{F} 3$ cells. Note that the weaker pattern of phosphorylation seen in the $\mathrm{mTEL}-J a k 2$ line is due to underloading of total cell lysates.

cellular extracts (Figure 2B). We failed to detect any consistent IL-3 $\beta R$ phosphorylation in TEL-JAK-expressing cell lines, whereas a constitutive phosphorylation was observed in cells transformed by the TEL-ABL fusion. These results suggest that growth signals derived from TEL-JAK proteins do not involve cooperation with the IL-3 $\beta R$ chain. In contrast, TEL-ABL proteins phosphorylate the IL-3 $\beta R$ chain, but the relevance of this phosphorylation to their transforming capacities is not known. From these observations, one can infer that TEL-JAK proteins have lost some substrate specificity with respect to normal JAK proteins and that TEL-ABL proteins exhibit a wider substrate specificity than TEL-JAKs. In keeping with these results, Western blot analysis of total cell lysates showed a different pattern of phosphorylated protein species between the 
IL-3-independent TEL-JAK- and TEL-ABL-expressing cells (Figure 2C).

\section{All TEL-JAK fusion proteins induce functional activation of Stat5 factors}

To determine if the different TEL-JAK fusions selectively activate members of the Stat family, Stat DNA binding activities were analyzed by EMSA. Nuclear extracts from the TEL-JAK- and TEL-ABL-expressing lines were incubated with probes containing various Stat binding sequences, known to have different affinities for activated Stats. The $\beta$-casein probe contains Stat 5 binding sites and binds the 2 highly homologous Stat5A and Stat5B factors. ${ }^{16}$ As a positive control, parental $\mathrm{Ba} / \mathrm{F} 3$ cells were stimulated with recombinant murine IL-3 (mIL-3). As shown in Figure 3A, nuclear extracts from all TEL-JAK-transformed cell lines showed a specific Stat5 DNA binding activity, consisting of a major proteinDNA complex, which can be supershifted with anti-Stat5 antibodies (Figure 3A, compare lanes 4, 7, 10, 13, and 16 to lanes 6, 9, 12, 15 , and 18 , respectively). Specificity of Stat5- $\beta$-casein complexes

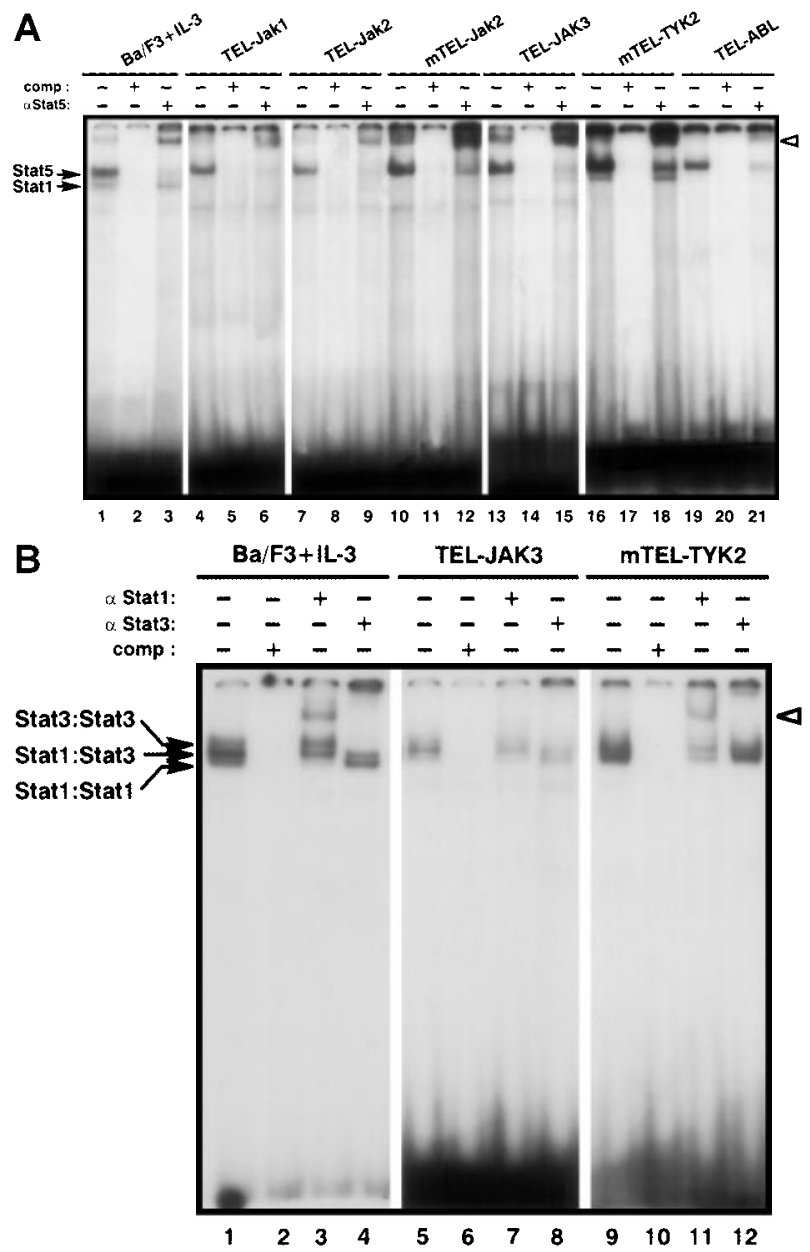

Figure 3. Constitutive activation of Stat factors in TEL-JAK-transformed Ba/F3 cells. Analyses of Stat DNA-binding activities in IL-3-independent $\mathrm{Ba} / \mathrm{F} 3$ cells expressing the indicated constructs. As a control for Stat1, Stat3, and Stat5 DNA-binding activities, nontransfected $\mathrm{Ba} / \mathrm{F} 3$ cells were starved for 5 hours, then stimulated with $10 \mathrm{ng} / \mathrm{mL}$ of $\mathrm{mlL}-3$ for 10 minutes. Nuclear extracts were submitted to EMSA using the bovine $\beta$-casein (A) and m67SIE (B) probes. The specificity of the shifted complexes was assessed by the addition of a 100-fold molar excess of cold competitors. Complexes supershifted by specific anti-Stat factors antibodies are indicated by open arrows. Note that constitutive Stat 1 and Stat3 activations detected in TEL-JAK3-expressing Ba/F3 cells were observed after prolonged exposure. was confirmed by competitive experiments using unlabeled $\beta$-casein probe (Figure 3A, lanes 5, 8, 11, 14, and 17). Nonrelevant competitors did not interfere with the shifted complexes (data not shown). Both Stat5A and Stat5B factors are expressed in $\mathrm{Ba} / \mathrm{F} 3$ cells but a more pronounced Stat5A DNA binding activity was observed in all transformed $\mathrm{Ba} / \mathrm{F} 3$ cells. In nuclear extracts from TEL-JAK3 (Figure 3A, lane 13) and mTEL-TYK2 (Figure 3A, lane 16), a faint signal corresponding to a higher mobility complex was observed, similar to the one seen after mIL-3-stimulation (Figure 3A, lane 1). This complex corresponds to Stat1, because the $\beta$-casein probe is known to exhibit low affinity for Stat 1 factors, which are activated in $\mathrm{Ba} / \mathrm{F} 3$ cells on IL-3 stimulation. ${ }^{17}$ Furthermore, supershifting experiments with an anti-Stat1 antibody confirmed the specific interactions of Stat 1 with the $\beta$-casein probe with these extracts (data not shown). A constitutive activation of Stat5 factors was also seen in TEL-ABL-transformed cells (Figure $3 \mathrm{~A}$, lanes 19-21). In addition, Stat5 is activated in TEL-PDGF $\beta$ Rtransformed cells (A.B., unpublished data). Collectively, these results establish the recurrent activation of Stat5 DNA binding activity in $\mathrm{Ba} / \mathrm{F} 3$ cells for all TEL-fusion proteins studied to date.

\section{Stat 1 and Stat 3 are activated in $\mathrm{Ba} / \mathrm{F} 3$ cells transformed by the TEL-JAK3, mTEL-TYK2, and TEL-ABL fusions}

Specific activation of Stat 1 and Stat 3 factors was assessed by using the high affinity m67SIE sequence, derived from the STAT binding motif of the c-fos promoter $^{18}$ (Figure 3B). This probe allows the formation of 3 DNA-protein species that correspond to homodimers of Stat1, homodimers of Stat3, and heterodimers of Stat1 and Stat3. Constitutive activation of both factors was observed in the TEL-JAK3-, mTEL-TYK2-, and TEL-ABL-expressing cells. Nuclear extracts from TEL-JAK3-transformed Ba/F3 cells showed patterns of protein-DNA complexes and of supershifts with antiStat 1 and anti-Stat 3 antibodies similar to those observed with mIL-3-stimulated cells extracts used as control (Figure 3B, compare lanes 1-4 to 5-8, respectively). Nuclear extracts from the mTEL-TYK2-expressing cells only formed 2 shifted DNA-protein complexes with a high degree of specificity as shown by competition with excess cold m67SIE probe (Figure 3B, compare lanes 9 and 10) and incubation with an anti-Stat 1 antibody confirmed the presence of Stat1 factors in the low migrating DNA-protein complex. The presence of 2 shifted complexes indicated that some Stat 3 was activated in these extracts and preferentially associated with Stat1 to form Stat1-Stat3 heterodimers, although the use of an anti-Stat3 antibody did not clearly reveal a Stat3 DNA binding activity (Figure 3B, lane 11). It is noteworthy that lower levels of activated Stat1 factors were observed in TEL-JAK3-expressing cells, as compared to mTEL-TYK2-expressing cells (Figure 3B, compare lanes 5 and 9). Minor Stat 1 and Stat 3 activations were also evidenced in nuclear extracts from $\mathrm{Ba} / \mathrm{F} 3$ cells expressing the TEL-ABL fusion (data not shown).

Stat4 and Stat6 DNA binding activities were investigated using the specific Fc $\gamma$ RI and I $\epsilon$ probes, respectively, but these factors were not found to be activated in TEL-JAK and TEL-ABLtransformed cell lines despite the fact that both are present in $\mathrm{Ba} / \mathrm{F} 3$ cells (data not shown).

\section{A specific set of cytokine-responsive genes is induced in the TEL-JAK-transformed $\mathrm{Ba} / \mathrm{F} 3$ cell lines}

To further investigate the molecular events leading to growth factor independence conferred by TEL-JAK fusions in the Ba/F3 cellular context, we examined by Northern blot the induction of a series of 
cytokine-responsive genes, including genes whose products are involved in the control of cellular proliferation. Parental $\mathrm{Ba} / \mathrm{F} 3$ cells cultured in the presence of WEHI conditioned medium, as a source of growth factors, will be referred to as proliferating cells. The c-myc, c-jun, and c-fos genes are immediate early genes induced in response to IL-3 in $\mathrm{Ba} / \mathrm{F} 3$ cells $^{19}$ and the cytokinedriven activation of both c-myc and c-fos transcription has been directly linked to the activation of JAK pathways. ${ }^{20,21}$ All TEL-JAKexpressing cells exhibited elevated levels of c-myc, c-jun, and c-fos expression, equivalent to those found in proliferating parental cells, indicating that expression of chimeric proteins efficiently substitute for the normal IL-3-mediated mitogenic signals. Thus, it appears that signaling pathways activated by the leukemogenic TEL-Jak2 protein and by the chimeric TEL-JAK fusions studied here can mimic at least some of the events triggered by the cytokinereceptor interaction. In contrast, the expression of TEL-ABL resulted in high expression levels of c-fos, c-jun, and c-myc, because messenger RNA (mRNA) levels were found to be 2, 2.5, and 3 times higher, respectively, as compared to those seen in proliferating parental cells. These findings are in agreement with previous reports indicating that c-myc expression is up-regulated in $\mathrm{Ba} / \mathrm{F} 3$ cells transformed by the TEL-ABL fusion. ${ }^{22}$

The constitutive activation of Stat5 in all transformed $\mathrm{Ba} / \mathrm{F} 3$ cell lines prompted us to examine the induction of several known Stat5-target genes in these cells. Among them, those encoding oncostatin $\mathrm{M}$ (osm), the hematopoietic serine/threonine kinase pim-1, and the cytokine-inducible $\mathrm{SH}$-containing (Cis) protein involved in switching off the cytokine signal by interacting with phosphorylated tyrosine residues on receptor chains, ${ }^{23}$ are normally activated via Stat5-dependent pathways. ${ }^{14,24-26}$ As shown in Figure 4, these Stat5-target genes were activated in TEL-JAK- and TEL-ABL-expressing cells, providing further evidence of a functional constitutive Stat5 activation in the cytokine-independent cell lines. Interestingly, although transcriptionnal levels of both osm and pim-1 genes were equivalent in the transformed $\mathrm{Ba} / \mathrm{F} 3$ cell lines to those of proliferating parental cells, levels of Cis expression were significantly higher. The mechanisms underlying the sustained expression of Cis remain, however, to be established.

\section{Constitutive expression of a dominant negative form of Stat5A in $\mathrm{Ba} / \mathrm{F} 3$ cells significantly interferes with the growth factor independence process mediated by TEL-Jak2}

To further establish the importance of Stat5 activation for the mitogenic properties of TEL-Jak2, we next analyzed the ability of a Stat5A dominant negative mutant to interfere with TEL-Jak2 transforming properties. The Stat5A $\Delta 749$ protein lacks the carboxy terminal transactivation domain of Stat5 and exerts a dominant negative effect on Stat5-responsive gene promoters. ${ }^{27}$ The pRSVNeo-Stat5A $\Delta 749 \mathrm{Ba} / \mathrm{F} 3$ cells ${ }^{12}$ were stably transfected with the pBabePuro-TEL-Jak2 expressing vector (Stat5A $\Delta 749+$ TEL-Jak2 transfectants) or with empty vector (Stat5A $\Delta 749+$ pBabePuro transfectants). TEL-Jak2 cells harboring the pRSVNeo control vector were also established (Neo+TEL-Jak2 transfectants). The numbers of viable cells of the different transfectants were scored daily in the presence or in the absence of IL-3 and are shown in Figure 5. The Neo+TEL-Jak2 cells grew efficiently when deprived of IL-3, whereas parental Stat5A $\Delta 749$ and Stat5A $\Delta 749+$ pBabePuro cell lines were unable to proliferate in similar conditions (Figure 5B). The Stat5A $\Delta 749+$ TEL-Jak2 cells showed poor proliferation rates in the absence of IL-3. These data demonstrate that the expression of a dominant negative Stat5 mutant markedly inter-

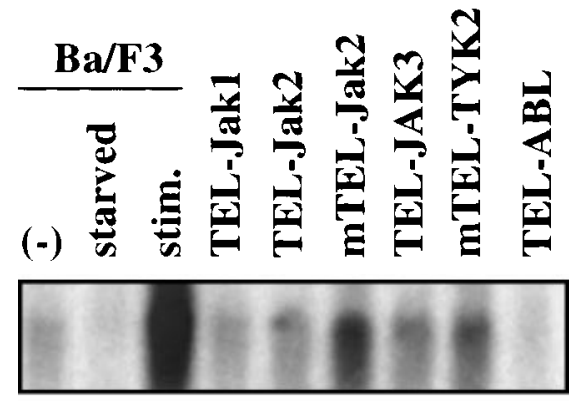

pim-1

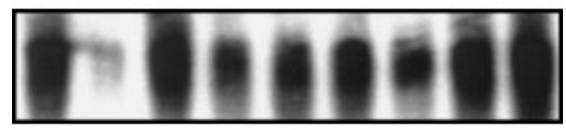

cis

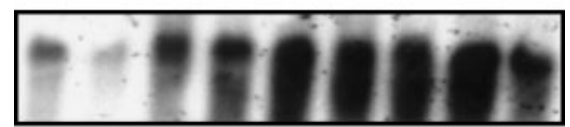

$\begin{array}{lllllllll}1 & - & 5 & 2 & 5 & 4 & 4 & 7 & 4\end{array}$

\section{GAPDH}

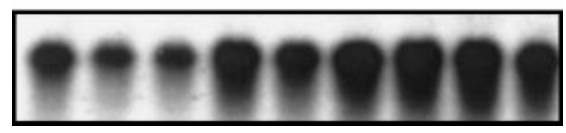

Figure 4. Induction of several Stat5-target genes in TEL-JAK- and TEL-ABLtransformed $\mathrm{Ba} / \mathrm{F} 3$ cells. Northern blot analyses of total RNA extracted from the indicated cell lines for osm, pim-1, and Cis expression are shown. RNA from $\mathrm{Ba} / \mathrm{F3}$ cells cultured in the presence of WEHI conditioned medium (-), starved (starved), and stimulated by mIL-3 (stim) were loaded as controls. The indicated values of $\mathrm{Cis}$ induction are expressed relative to the values obtained by proliferating $\mathrm{Ba} / \mathrm{F} 3$ cells. $\mathrm{A}$ GAPDH probe was used as internal standard.

feres with the ability of TEL-Jak2 to induce growth factor independence to $\mathrm{Ba} / \mathrm{F} 3$ cells, strongly suggesting the requirement for Stat 5 activation in this process.

\section{Discussion}

Chromosomal translocations resulting in TEL-JAK2 fusion proteins have been reported in several human leukemias. ${ }^{7,8}$ The TEL-JAK2 fusion proteins described to date transform growth factor-dependent cell lines and are leukemogenic in mouse mod-
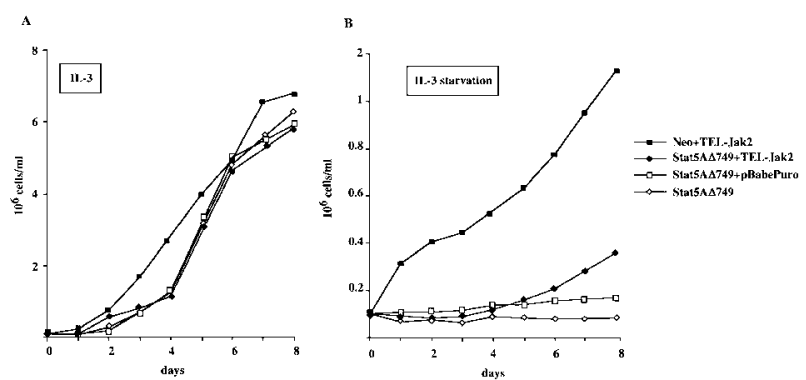

Figure 5. The constitutive expression of a dominant negative Stat5A mutant interferes with the growth factor independence conferred by the TEL-Jak2 fusion in $\mathbf{B a} / \mathbf{F} 3$ cells. $\mathrm{Ba} / \mathrm{F} 3$ cells constitutively expressing the pRSVNeoStat5A $\Delta 749$ vector (Stat5A $\Delta 749$ ) were stably transfected with TEL-Jak2 (Stat5A $\Delta 749+$ TEL-Jak2) or the empty expression vector (Stat5A $\Delta 749+\mathrm{pBabePuro}$ ). As a control, the parental pRSVNeo Ba/F3 cells were stably transfected by TEL-Jak2 (Neo+TEL-Jak2). The proliferation rates of the indicated Ba/F3 cell lines were scored daily for 8 days in either the presence (A) or absence (B) of WEHI conditioned medium. 
els $^{7,28}$ (and our unpublished data). Several examples of tyrosine kinases constitutively activated through ectopic oligomerization have been reported in human hematopoietic malignancies, one of the most extensively studied being the BCR-ABL fusion protein in chronic myelogenous leukemia with the Philadelphia chromosome. ${ }^{29}$ Thus, the identification of signaling molecules regulated by these kinases is essential to elucidate the mechanisms underlying their transforming and leukemogenic properties.

We generated TEL-JAK chimeric proteins by fusing the oligomerization domain of TEL to the catalytic domains (JH1) of Jak1, JAK3, or TYK2. The TEL-JAK fusions were constitutively phosphorylated both in vitro and in vivo, showing that TEL-mediated oligomerization is sufficient to induce their constitutive tyrosine kinase activity. When stably expressed in $\mathrm{Ba} / \mathrm{F} 3$ cells, all TEL-JAK chimera were able to sustain cytokine-independent cellular growth, indicating that they can substitute for growth factor-mediated signals. These results are somewhat unexpected because, except for JAK2, JAK kinases are presumed to normally signal in pairs when activated under physiologic conditions. Furthermore, the JH2 domain is dispensable for the biologic properties of all chimeras tested, including mTEL-TYK2, whereas it is known to be required for the normal kinase activity of TYK2. ${ }^{30}$ Activation through oligomerization is, however, not a feature of all JAK tyrosine kinase domains because a TEL-DJAK fusion, containing the JH1 domain of the homologous Drosophila Hopscotch protein, did not exhibit detectable tyrosine phosphorylation in vitro nor transforming properties in $\mathrm{Ba} / \mathrm{F} 3$ cells (unpublished data). Whether its lack of activity is due to the absence of the $\mathrm{JH} 2$, as previously observed, ${ }^{31}$ or to structural particularities of the DJAK JH1 remains to be determined.

As reported for TEL-Jak2, ${ }^{7}$ TEL-JAK fusion proteins have a diffuse cytoplasmic location (data not shown) that differs from normal activated JAK proteins, which are associated with the intracellular moiety of cytokine receptors. Accordingly, phosphorylated substrates could differ between the TEL-JAK and JAK proteins. For example, the IL-3 $\beta R$ chain is not detectably tyrosine phosphorylated in $\mathrm{Ba} / \mathrm{F} 3$ cells expressing the TEL-JAK fusions. Phosphorylation of normal JAK proteins is not seen or inconsistently detected (data not shown). ${ }^{28,32}$ Consistently, functional studies of artificially activated forms of JAK2 have suggested that the tyrosine kinase domain is not sufficient to interact with and phosphorylate the granulocyte macrophage colony-stimulating factor (GM-CSF) receptor, ${ }^{33}$ the IL-3 receptor, ${ }^{34}$ or the growth hormone receptor. ${ }^{35}$ These observations suggest that TEL-JAK fusions are able to directly activate signaling pathways that lead to cell proliferation or inhibition of apoptosis independently of the cytokine receptor activation or the use of receptor effector domain as accessory signaling chain.

In keeping with this hypothesis, constitutive activation of STAT factors is observed in $\mathrm{Ba} / \mathrm{F} 3$ cells transformed by the TEL-JAK fusions. A number of studies have suggested that specificity of STAT factors activation in response to cytokine receptor engagement is more related to the nature of the cytokine receptor involved than to the activation of a particular JAK. This notion might, however, not be so absolute because a ligand-independent interaction between the $\mathrm{SH} 2$ domain of Stat5 and the JAKs has been reported. ${ }^{36}$ Also, complexes between the $\mathrm{SH} 2$ region of Stat5 and phosphotyrosine residues located in the $\mathrm{JH} 1$ region of JAK2 occurred when these proteins are expressed in yeast cells, ${ }^{37}$ suggesting the possibility of a direct recruitment of Stat5 to the activated kinase, independent of receptor docking. Similarly, the
$\mathrm{SH} 2$ region of Stat1 has been reported to directly interact with the activated TYK2 kinase. ${ }^{38}$ Moreover, we observed a selective activation of Stat 1 and Stat 3 in $\mathrm{Ba} / \mathrm{F} 3$ cells expressing the TEL-JAK3 and mTEL-TYK2 fusions, whose cellular counterparts preferentially activate these factors in a number of cytokine receptor systems. Accordingly, only the JH1 regions of JAK3 and TYK2 possess 2 potential functional Stat 3 binding sites centered on $\mathrm{Y}^{824}$ and $\mathrm{Y}^{1176}$, respectively, which conformed to the previously identified Stat3 docking sites on cytokine receptors (YXXQ, preceded by acid amino acids ${ }^{3}$ ). In keeping with our results, Ho et $\mathrm{al}^{32}$ recently reported the recurrent activation of Stat 5 in $\mathrm{Ba} / \mathrm{F} 3$ cells expressing TEL-Jak2 fusions, but also constitutive activation of Stat 1 and Stat3. In this instance, detection of activated Stat 1 and Stat 3 factors could be related to higher levels of expression of transforming proteins in $\mathrm{Ba} / \mathrm{F} 3$ cells than in our model or to differences in $\mathrm{Ba} / \mathrm{F} 3$ sublines used.

The comparison of $\mathrm{Ba} / \mathrm{F} 3$ cells expressing either the TEL-JAK or the TEL-ABL fusion proteins reveals several interesting features. In contrast to those expressing TEL-JAK, Ba/F3 cells transformed by the TEL-ABL fusion protein exhibit constitutive phosphorylation of the IL-3 $\beta R$ chain (see Figure $2 B$ ) and of endogenous JAK2 protein (data not shown). Similar observations have been reported for hematopoietic cells transformed by the BCR-ABL fusion proteins, ${ }^{39,40}$ raising the possibility that abrogation of growth factor requirement of hematopoietic cell lines expressing these kinases may, at least partially, involve the activation of cytokine receptors. On the other hand, this phosphorylation could merely reflect the weak substrate specificity of the oncogenic forms of ABL fusion proteins. Alternatively, one cannot exclude that the cytoskeletal-associated localization of TEL-ABL ${ }^{9}$ allows, therefore, the phosphorylation of membrane-bound proteins by the chimera. In keeping with this hypothesis, the SHP1 phosphatase is heavily tyrosine phosphorylated in TEL-ABL but not detectably in TEL-JAK-expressing Ba/F3 (data not shown). The distinct pattern of tyrosine phosphorylated proteins observed in TEL-JAK- and TEL-ABL-expressing cells (see Figure 2C) further underlines the different substrate specificity of these activated TEL-derived fusion kinases.

Transcription of genes whose products are involved in cellular growth regulation also differs between TEL-JAK- and TEL-ABLexpressing $\mathrm{Ba} / \mathrm{F} 3$. In keeping with our results, high levels of transcription of the early response genes c-myc and c-fos have been reported in $\mathrm{Ba} / \mathrm{F} 3$ cells expressing TEL-ABL ${ }^{22}$ and in cell lines expressing BCR-ABL. ${ }^{41}$ From our data, the cytokine-independent proliferation of TEL-JAK-transformed $\mathrm{Ba} / \mathrm{F} 3$ cells is not associated with higher level of expression of the early-response c-myc, c-jun, and c-fos genes, because these genes were expressed at levels lower than those observed in TEL-ABL-expressing cells but similar to those observed in exponentially growing parental $\mathrm{Ba} / \mathrm{F} 3$ cells. Several cytokine receptor models have demonstrated that induction of c-jun and c-fos expression requires not only JAK kinases activation but also the phosphorylation of several tyrosine residues of the activated receptor. ${ }^{42}$ Consistently, the absence of IL-3 $\beta R$ chain phosphorylation may explain the lower level of early gene induction in the TEL-JAK-expressing cells compared to TEL-ABL. Alternatively, interactions of TEL-ABL or TEL-JAK chimera with other signaling molecules known to participate to early gene induction ${ }^{20,21}$ could differ.

Finally, our results point to a pivotal role for Stat5 activation in the growth factor independence processes. Constitutive activation of STATs, particularly of Stat1, Stat3, and Stat5, is a recurrent 
observation in hematopoietic cell lines transformed by oncogenes such as v-abl, $B C R-A B L, \mathrm{v}-m p l$, and in leukemogenic blood samples (review in Garcia and Jove ${ }^{4}$ ). Stat5 activation is observed in all transformed $\mathrm{Ba} / \mathrm{F} 3$ cells lines, including those expressing the TEL-ABL (see Figure 3A) and TEL-PDGFßR fusions (unpublished data) and those expressing the various TEL-JAK fusion proteins, suggesting its direct contribution to cellular transformation. Experiments using a dominant negative Stat5A mutant (see Figure 5) strongly support this hypothesis. In this respect, Stat5 can be considered as the prototype of transcription factor implicated in all pleiotropic cytokine-induced cellular responses. It is activated by cytokines that regulate the proliferation and differentiation in all hematopoietic lineages (review in Pellegrini and Dusanter-Fourt ${ }^{3}$ ). Stat5 is assumed to regulate genes whose products are involved in the control of cellular growth, ${ }^{43}$ of cell cycle progression including cyclins, ${ }^{44,45}$ p21WAF1/CIP1, ${ }^{46}$ and possibly p $27^{47}$ and of apopto- sis. 12,48,49 Furthermore, the expression of a mutated Stat5 is sufficient to allow growth factor independent proliferation of $\mathrm{Ba} / \mathrm{F} 3$ cells. ${ }^{50}$

The constitutive activation of Stat5 factors is, therefore, likely to represent a crucial event in the activated tyrosine kinasemediated leukemogenic process. The availability of Stat5A- and Stat5B-deficient mice will allow us to establish in vivo the functional role of these factors in the transforming properties of the fusion proteins.

\section{Acknowledgments}

The authors thank N. Perrimon for providing the Hopscotch cDNA and the LPH from the Hôpital Saint-Louis (Paris, France) for artwork.

\section{References}

1. Ihle JN, Nosaka T, Thierfelder W, Quelle FW, Shimoda K. Jaks and Stats in cytokine signaling. Stem Cells. 1997;1:105-111.

2. Darnell JE Jr. STATs and gene regulation. Science. 1997;277:1630-1635

3. Pellegrini S, Dusanter-Fourt I. The structure, regulation and function of the Janus kinases (JAKs) and the signal transducers and activators of transcription (STATs). Eur J Biochem. 1997; 248:615-633.

4. Garcia R, Jove R. Activation of STAT transcription factors in oncogenic tyrosine kinase signaling. J Biomed Sci. 1998;5:79-85.

5. Bromberg JF, Horvath CM, Besser D, Lathem WW, Darnell JE Jr. Stat3 activation is required for cellular transformation by v-src. Mol Cell Biol. 1998;18:2553-2538.

6. Turkson J, Bowman T, Garcia R, Caldenhoven E, De Groot RP, Jove R. Stat3 activation by Src induces specific gene regulation and is required for cell transformation. Mol Cell Biol. 1998;18:25452552.

7. Lacronique V, Boureux A, Valle VD, et al. A TELJAK2 fusion protein with constitutive kinase activity in human leukemia. Science. 1997;278:13091312.

8. Peeters P, Raynaud SD, Cools J, et al. Fusion of TEL, the ETS-variant gene 6 (ETV6), to the receptor-associated kinase JAK2 as a result of $t(9$; $12)$ in a lymphoid and $t(9 ; 15 ; 12)$ in a myeloid leukemia. Blood. 1997;90:2535-2540.

9. Golub TR, Goga A, Barker GF, et al. Oligomerization of the ABL tyrosine kinase by the Ets protein TEL in human leukemia. Mol Cell Biol. 1996;16: 4107-4116.

10. Jousset C, Carron C, Boureux A, et al. A domain of TEL conserved in a subset of ETS proteins defines a specific oligomerization interface essential to the mitogenic properties of the TEL-PDGFR beta oncoprotein. EMBO J. 1997;16:69-82.

11. Carroll M, Tomasson MH, Barker GF, Golub TR, Gilliland DG. The TEL/platelet-derived growth factor beta receptor (PDGF beta $\mathrm{R}$ ) fusion in chronic myelomonocytic leukemia is a transforming protein that self-associates and activates PDGF beta $R$ kinase-dependent signaling pathways. Proc Natl Acad Sci U S A. 1996;93:14,84514,850 .

12. Dumon S, Santos SC, Debierre-Grockiego F, et al. IL-3 dependent regulation of $\mathrm{Bcl}-\mathrm{xL}$ gene expression by STAT5 in a bone marrow derived cell line [In Process Citation]. Oncogene. 1999;18: 4191-4199.

13. Pallard C, Gouilleux F, Benit L, et al. Thrombopoi- etin activates a STAT5-like factor in hematopoietic cells. EMBO J. 1995;14:2847-2856.

14. Verdier F, Rabionet R, Gouilleux F, et al. A sequence of the CIS gene promoter interacts preferentially with two associated STAT5A dimers: a distinct biochemical difference between STAT5A and STAT5B. Mol Cell Biol. 1998;18:5852-5860.

15. Poirel $\mathrm{H}$, Oury $\mathrm{C}$, Carron $\mathrm{C}$, et al. The TEL gene products: nuclear phosphoproteins with DNA binding properties. Oncogene. 1997;14:349-357.

16. Gouilleux F, Wakao H, Mundt M, Groner B. Prolactin induces phosphorylation of Tyr694 of Stat5 (MGF), a prerequisite for DNA binding and induction of transcription. EMBO J. 1994;13:43614369.

17. Nagata $Y$, Todokoro $K$. Interleukin 3 activates not only JAK2 and STAT5, but also Tyk2, STAT1, and STAT3. Biochem Biophys Res Commun. 1996; 221:785-789.

18. Wagner BJ, Hayes TE, Hoban CJ, Cochran BH. The SIF binding element confers sis/PDGF inducibility onto the c-fos promoter. EMBO J. 1990;9: 4477-4484.

19. Miyajima A, Mui AL, Ogorochi T, Sakamaki K. Receptors for granulocyte-macrophage colonystimulating factor, interleukin-3, and interleukin-5. Blood. 1993;82:1960-2974.

20. Takeshita T, Arita T, Higuchi M, et al. STAM, sig nal transducing adaptor molecule, is associated with Janus kinases and involved in signaling for cell growth and c-myc induction. Immunity. 1997; 6:449-457.

21. Yamashita Y, Watanabe S, Miyazato A, et al. Tec and Jak2 kinases cooperate to mediate cytokinedriven activation of c-fos transcription. Blood. 1998;91:1496-1507.

22. Hannemann JR, McManus DM, Kabarowski JH, Wiedemann LM. Haemopoietic transformation by the TEL/ABL oncogene. Br J Haematol. 1998; 102:475-485.

23. Yoshimura A, Ohkubo T, Kiguchi T, et al. A novel cytokine-inducible gene $\mathrm{CIS}$ encodes an $\mathrm{SH} 2$ containing protein that binds to tyrosine-phosphorylated interleukin 3 and erythropoietin receptors. EMBO J. 1995;14:2816-2826.

24. Yoshimura A, Ichihara M, Kinjyo I, et al. Mouse oncostatin M: an immediate early gene induced by multiple cytokines through the JAK-STAT5 pathway. EMBO J. 1996;15:1055-1063.

25. Mui AL, Wakao H, Kinoshita T, Kitamura T, Miyajima A. Suppression of interleukin-3-induced gene expression by a C-terminal truncated Stat5: role of Stat5 in proliferation. EMBO J. 1996;15: 2425-2433.
26. Matsumoto A, Masuhara M, Mitsui K, et la. CIS, a cytokine inducible $\mathrm{SH} 2$ protein, is a target of the JAK-STAT5 pathway and modulates STAT5 activation. Blood. 1997;89:3148-3154.

27. Moriggl R, Gouilleux-Gruart V, Jahne R, et al. Deletion of the carboxyl-terminal transactivation domain of MGF-Stat5 results in sustained DNA binding and a dominant negative phenotype. Mol Cell Biol. 1996;16:5691-5700.

28. Schwaller J, Frantsve J, Aster J, et al. Transformation of hematopoietic cell lines to growth-factor independence and induction of a fatal myelo- and lymphoproliferative disease in mice by retrovirally transduced TEL/JAK2 fusion genes. EMBO J. 1998;17:5321-5333.

29. Sawyers CL. Signal transduction pathways involved in $\mathrm{BCR}-\mathrm{ABL}$ transformation. Baillieres Clin Haematol. 1997;10:223-231.

30. Velazquez L, Mogensen KE, Barbieri G, Fellous M, Uze G, Pellegrini S. Distinct domains of the protein tyrosine kinase tyk2 required for binding of interferon-alpha/beta and for signal transduction. J Biol Chem. 1995;270:3327-3334.

31. Luo $\mathrm{H}$, Rose $\mathrm{P}$, Barber $\mathrm{D}$, et al. Mutation in the Jak kinase JH2 domain hyperactivates Drosophila and mammalian Jak-Stat pathways. Mol Cell Biol. 1997;17:1562-1571.

32. Ho JM, Beattie BK, Squire JA, Frank DA, Barber $\mathrm{DL}$. Fusion of the ets transcription factor TEL to Jak2 results in constitutive Jak-Stat signaling. Blood. 1999;93:4354-4364.

33. Zhao Y, Wagner F, Frank SJ, Kraft AS. The amino-terminal portion of the JAK2 protein kinase is necessary for binding and phosphorylation of the granulocyte-macrophage colony-stimulating factor receptor beta c chain. J Biol Chem. 1995; 270:13,814-13,818

34. Mohi MG, Arai K, Watanabe S. Activation and functional analysis of Janus kinase 2 in BA/F3 cells using the Coumermycin/Gyrase B system. Mol Biol Cell. 1998;9:3299-3308.

35. Frank SJ, Yi W, Zhao Y, et al. Regions of the JAK2 tyrosine kinase required for coupling to the growth hormone receptor. J Biol Chem. 1995; 270:14,776-14,785

36. Fujitani Y, Hibi M, Fukada T, et al. An alternative pathway for STAT activation that is mediated by the direct interaction between JAK and STAT. Oncogene. 1997;14:751-761.

37. Barahmand-Pour F, Meinke A, Groner B, Decker T. Jak2-Stat5 interactions analyzed in yeast. J Biol Chem. 1998;273:12,567-12,575.

38. Gupta S, Yan H, Wong LH, Ralph S, Krolewski J, Schindler C. The SH2 domains of Stat1 and Stat2 
mediate multiple interactions in the transduction of IFN-alpha signals. EMBO J. 1996;15:10751084

39. Wilson-Rawls J, Xie S, Liu J, Laneuville P, Arlinghaus RB. P210 Bcr-Abl interacts with the interleukin 3 receptor beta(c) subunit and constitutively induces its tyrosine phosphorylation. Cancer Res. 1996;56:3426-3430.

40. Ilaria RL Jr, Van Etten RA. P210 and P190(BCR/ $A B L$ ) induce the tyrosine phosphorylation and DNA binding activity of multiple specific STAT family members. J Biol Chem. 1996;271:31,70431,710 .

41. Sawyers CL, Callahan W, Witte ON. Dominant negative MYC blocks transformation by $A B L$ oncogenes. Cell. 1992;70:901-910.

42. Itoh T, Liu R, Yokota T, Arai KI, Watanabe S. Definition of the role of tyrosine residues of the common beta subunit regulating multiple signaling pathways of granulocyte-macrophage colonystimulating factor receptor. Mol Cell Biol. 1998;18: 742-752.

43. Welte T, Leitenberg D, Dittel BN, et la. STAT5 interaction with the $T$ cell receptor complex and stimulation of T cell proliferation. Science. 1999; 283:222-225.

44. Matsumura I, Kitamura T, Wakao H, et al. Transcriptional regulation of the cyclin D1 promoter by STAT5: its involvement in cytokine-dependent growth of hematopoietic cells. EMBO J. 1999;18: 1367-1377.

45. Moriggl R, Topham DJ, Teglund S, et al. Stat5 is required for IL-2-induced cell cycle progression of peripheral T cells. Immunity. 1999;10:249-259.

46. Matsumura I, Ishikawa J, Nakajima K, et al. Thrombopoietin-induced differentiation of a human megakaryoblastic leukemia cell line, CMK, involves transcriptional activation of p21(WAF1)
Cip1) by STAT5. Mol Cell Biol. 1997;17:29332943.

47. Teglund S, McKay C, Schuetz E, et al. Stat5a and Stat5b proteins have essential and nonessential, or redundant, roles in cytokine responses. Cell. 1998;93:841-850.

48. Zamorano J, Wang HY, Wang R, Shi Y, Longmore $\mathrm{GD}$, Keegan AD. Regulation of cell growth by IL-2: role of STAT5 in protection from apoptosis but not in cell cycle progression. J Immunol. 1998:160:3502-3512.

49. Socolovsky M, Fallon AE, Wang S, Brugnara C, Lodish HF. Fetal anemia and apoptosis of red cell progenitors in Stat5a-/-5b-/- mice: a direct role for Stat5 in Bcl-X(L) induction. Cell. 1999;98:181 191.

50. Onishi M, Nosaka T, Misawa K, et al. Identification and characterization of a constitutively active STAT5 mutant that promotes cell proliferation. Mol Cell Biol. 1998;18:3871-3879. 